\title{
A laser-induced fluorescence instrument for aircraft measurements of sulfur dioxide in the upper troposphere and lower stratosphere
}

\author{
Andrew W. Rollins ${ }^{1,2}$, Troy D. Thornberry ${ }^{1,2}$, Steven J. Ciciora ${ }^{2}$, Richard J. McLaughlin ${ }^{1,2}$, Laurel A. Watts ${ }^{1,2}$, \\ Thomas F. Hanisco ${ }^{3}$, Esther Baumann ${ }^{4}$, Fabrizio R. Giorgetta ${ }^{4}$, Thaopaul V. Bui ${ }^{5}$, David W. Fahey ${ }^{1,2}$, and \\ Ru-Shan Gao $^{2}$ \\ ${ }^{1}$ Cooperative Institute for Research in Environmental Sciences, Boulder, CO, USA \\ ${ }^{2}$ NOAA Earth System Research Laboratory, Chemical Sciences Division, Boulder, CO, USA \\ ${ }^{3}$ NASA Goddard Space Flight Center, Greenbelt, MD, USA \\ ${ }^{4}$ National Institute of Standards and Technology, Boulder, CO, USA \\ ${ }^{5}$ NASA Ames Research Center, Moffett Field, CA, USA
}

Correspondence to: Andrew W. Rollins (andrew.rollins@ noaa.gov)

Received: 4 May 2016 - Published in Atmos. Meas. Tech. Discuss.: 19 May 2016

Revised: 6 August 2016 - Accepted: 25 August 2016 - Published: 20 September 2016

\begin{abstract}
This work describes the development and testing of a new instrument for in situ measurements of sulfur dioxide $\left(\mathrm{SO}_{2}\right)$ on airborne platforms in the upper troposphere and lower stratosphere (UT-LS). The instrument is based on the laser-induced fluorescence technique and uses the fifth harmonic of a tunable fiber-amplified semiconductor diode laser system at $1084.5 \mathrm{~nm}$ to excite $\mathrm{SO}_{2}$ at $216.9 \mathrm{~nm}$. Sensitivity and background checks are achieved in flight by additions of $\mathrm{SO}_{2}$ calibration gas and zero air, respectively. Aircraft demonstration was performed during the NASA VolcanoPlume Investigation Readiness and Gas-Phase and Aerosol Sulfur (VIRGAS) experiment, which was a series of flights using the NASA WB-57F during October 2015 based at Ellington Field and Harlingen, Texas. During these flights, the instrument successfully measured $\mathrm{SO}_{2}$ in the UT-LS at background (non-volcanic) conditions with a precision of $2 \mathrm{ppt}$ at $10 \mathrm{~s}$ and an overall uncertainty determined primarily by instrument drifts of $\pm(16 \%+0.9 \mathrm{ppt})$.
\end{abstract}

\section{Background}

Sulfur dioxide $\left(\mathrm{SO}_{2}\right)$ has long been recognized as an anthropogenic air pollutant and a precursor to aerosols throughout the atmosphere. $\mathrm{SO}_{2}$ is emitted directly by both natural (e.g., volcanoes, biomass burning) and anthropogenic (e.g., fossil fuel combustion) processes (Dentener et al., 2006; Lamarque et al., 2010), and additionally is produced from the gas-phase oxidation of other sulfur-bearing species (e.g., carbonyl sulfide, dimethyl sulfide, hydrogen sulfide). Once $\mathrm{SO}_{2}$ enters the atmosphere, it is converted by gas- and aqueous-phase chemistry to sulfate with a global average timescale of 12 weeks (Seinfeld and Pandis, 2006). This sulfate has negative impacts on human health via inhalation (Lelieveld et al., 2015) and on ecosystem health via deposition (Vet et al., 2014), and it also significantly offsets greenhouse-gasinduced climate warming (Myhre et al., 2013).

A number of questions with respect to chemical and microphysical sulfur processes in the atmosphere have recently arisen. In the troposphere, some experimental evidence suggests that the hydroxyl radical may not be the sole gas-phase oxidizer of $\mathrm{SO}_{2}$ (Mauldin III et al., 2012), prompting questions of the identities and importance of these other oxidants for the $\mathrm{SO}_{2}$ budget. Nucleation and growth of new particles in the troposphere are known to occur from clusters of water and sulfuric acid $\left(\mathrm{H}_{2} \mathrm{SO}_{4}\right)$ derived from $\mathrm{SO}_{2}$ oxidation, but the extent to which this binary homogeneous nucleation dominates this process in various locations is unclear (Kirkby et al., 2011; Kulmala et al., 2013). Aerosol-cloud interactions resulting from anthropogenic $\mathrm{SO}_{2}$ emissions are believed to be the largest negative term in the anthropogenic radiative forcing of climate; however the magnitude of this forcing is highly uncertain, and process studies are required to reduce the uncertainties (Stocker et al., 2013). 
Stratospheric sulfate aerosols are an important, and variable, term in Earth's energy budget (Solomon et al., 2011). Indirect evidence suggests that anthropogenic emissions of $\mathrm{SO}_{2}$ may be having an impact on the stratospheric aerosol burden, but this potential flux of $\mathrm{SO}_{2}$ is unconstrained by measurements in the tropical upper troposphere and lower stratosphere (UT-LS) where the $\mathrm{SO}_{2}$ would be entering the stratosphere (Hofmann et al., 2009; Randel et al., 2010; Vernier et al., 2011). Additionally, the changes in the aerosol size and spatial distributions that will result from specific stratospheric $\mathrm{SO}_{2}$ perturbations cannot be calculated with confidence due to uncertainties in microphysical and dynamical processes (e.g., Heckendorn et al., 2011; Pierce et al., 2010). As a result, there are significant uncertainties in the relationship between aerosol radiative forcing and the upward flux of sulfur mass to the stratosphere. These uncertainties affect confidence in proposed climate intervention measures that would seek to increase Earth's albedo by injecting $\mathrm{SO}_{2}$ into the stratosphere (McNutt et al., 2015).

Despite these outstanding research questions, high-quality in situ measurements of $\mathrm{SO}_{2}$ are not routine and, until this work, have not been reported in the tropical lower stratosphere, where mixing ratios are expected to be on the order of $1-10$ parts per trillion $\left(10^{-12} \mathrm{~mol} \mathrm{~mol}^{-1}\right.$, ppt). The commercially available and commonly used instruments for $\mathrm{SO}_{2}$ monitoring in polluted environments are based on pulsed fluorescence (PF). Photons from a xenon lamp ( 205-220 nm) are used to electronically excite $\mathrm{SO}_{2}$, resulting in measurable red-shifted fluorescence. This technique suffers limited precision and significant interferences from other pollutants such as nitric oxide and aromatic compounds due to the broadband nature of the excitation source. A number of chemical ionization mass spectrometry (CIMS) techniques have been used to measure $\mathrm{SO}_{2}$. These instruments can have high-precision and fast time resolution. For example Jurkat et al. (2016) recently reported a detection limit $(3 \sigma)$ of $25 \mathrm{ppt}$ for a $1 \mathrm{~s}$ measurement, and Fiedler et al. (2009) reported a $2 \sigma$ detection limit of $\sim 20$ ppt.

Laser-induced fluorescence (LIF) has previously been demonstrated to be a sensitive technique for measuring $\mathrm{SO}_{2}$, but due in part to the complexity of traditional laser systems, LIF has been used much less frequently than the PF or CIMS techniques, and to our knowledge no scientific analyses using acquired data have been reported in the literature. LIF was first reported as a technique for measuring atmospheric $\mathrm{SO}_{2}$ by Bradshaw et al. (1982). They mixed the $1064 \mathrm{~nm}$ output of a Nd $\mathrm{NAG}^{+}$laser with the frequency-doubled output of a dye laser at $10 \mathrm{~Hz}$ to achieve $10 \mathrm{~mW}$ of tunable light at $222.2 \mathrm{~nm}$. Fluorescence was collected from 252 to $268 \mathrm{~nm}$ to achieve a signal level of 550 photons s ${ }^{-1} \mathrm{ppb}^{-1} \mathrm{SO}_{2}$. A detection limit of 4 ppt for 20 min of integration was stated; however, no measurements in the atmosphere were reported. Matsumi et al. (2005) used the doubled output of an optical parametric oscillator pumped by a frequency-tripled $10 \mathrm{~Hz}$ $\mathrm{Nd}^{+}$YAG to achieve $10 \mathrm{~mW}$ of output at $220 \mathrm{~nm}$. Fluores-

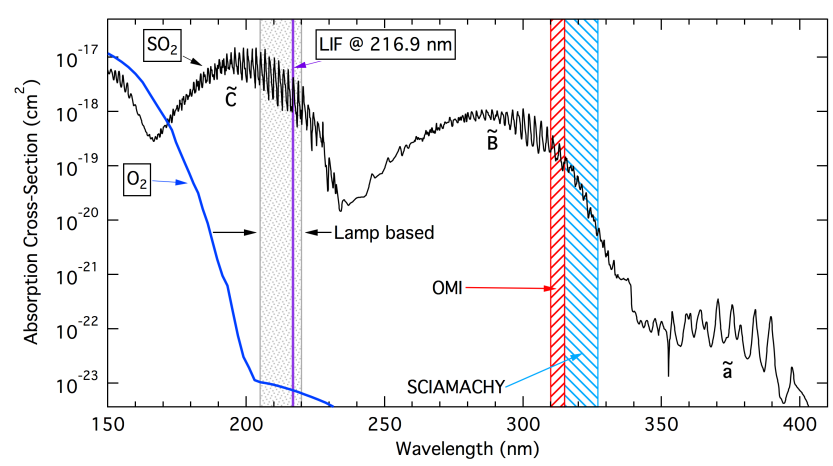

Figure 1. $\mathrm{SO}_{2}$ absorption spectrum compiled by Manatt and Lane (1993). The approximate region used in lamp-based $\mathrm{SO}_{2}$ fluorescence instrumentation $(205-220 \mathrm{~nm})$ is indicated by the shaded gray region, and the 216.9 used in this work indicated by the solid violet line. Spectral regions used by OMI (Ozone Monitoring Instrument) and SCIAMACHY (Scanning Imaging Absorption Spectrometer for Atmospheric Cartography) satellite instruments for column $\mathrm{SO}_{2}$ retrievals are indicated. Bands corresponding to excitations into the first three electronic excitations of $\mathrm{SO}_{2}$ are indicated by $\tilde{\mathrm{a}}, \widetilde{\mathrm{B}}$, and $\widetilde{\mathrm{C}}$.

cence from 240 to $440 \mathrm{~nm}$ was collected to achieve a signal level of 510 photons $\mathrm{s}^{-1} \mathrm{ppb}^{-1}$, and a detection limit of $5 \mathrm{ppt}$ for a $60 \mathrm{~s}$ integration was reported. Two hours of atmospheric data showed good agreement in comparison with a PF instrument at $\mathrm{SO}_{2}$ mixing ratios from 3.5-12 ppb.

We have made use of recent advances in laser technology to develop a LIF instrument with comparable sensitivity to CIMS and demonstrate it successfully on board the NASA WB-57F aircraft in the tropical UT-LS. In this work we describe the instrument and its initial performance in the UTLS during the NASA Volcano-Plume Investigation Readiness and Gas-Phase and Aerosol Sulfur (VIRGAS) mission in October 2015.

\section{Instrument}

\section{$2.1 \quad \mathrm{SO}_{2}$ spectroscopy}

The electronic structure of $\mathrm{SO}_{2}$ has been the subject of numerous experimental and theoretical studies. Figure 1 shows the $\mathrm{SO}_{2}$ spectrum from 150 to $410 \mathrm{~nm}$ and indicates which regions are used in this and other $\mathrm{SO}_{2}$ spectroscopic measurement schemes. At wavelengths less than $\sim 403 \mathrm{~nm}$ a series of absorption bands result in generally continuous and increasing absorption extending into the vacuum ultraviolet. Manatt and Lane (1993) presented a review of the available low-resolution absorption cross-section datasets from 106 to $403 \mathrm{~nm}$. Higher-resolution data extending from 198 to $325 \mathrm{~nm}$ have been acquired and reviewed by Stark et al. (1999) and Rufus et al. (2003). 
$\mathrm{SO}_{2}$ absorption bands resulting from transitions into at least three electronically excited states have relevance for detection and chemistry of atmospheric $\mathrm{SO}_{2}$. The lowest-lying excited state is the $\tilde{\mathrm{a}}\left({ }^{3} \mathrm{~B}_{1}\right)$ state above $24770 \mathrm{~cm}^{-1}(\sim 340 \mathrm{~nm}<\lambda<400 \mathrm{~nm})$. The maximum absorption cross section for the $\tilde{\mathrm{a}}\left({ }^{3} \mathrm{~B}_{1}\right) \leftarrow \widetilde{\mathrm{X}}\left({ }^{1} \mathrm{~A}_{1}\right)$ band is below $3.7 \times 10^{-22} \mathrm{~cm}^{2}$, and $\mathrm{SO}_{2}$ detection using this region of the spectrum has not been reported, although the chemical reactivity of $\mathrm{SO}_{2}$ in the ${ }^{3} \mathrm{~B}_{1}$ state has been thoroughly investigated (Calvert, 1984). The $\widetilde{\mathrm{B}}\left({ }^{1} \mathrm{~B}_{1}\right) \leftarrow \widetilde{\mathrm{X}}\left({ }^{1} \mathrm{~A}_{1}\right)$ region from $\sim 240$ to $338 \mathrm{~nm}$ has maximum absorption near $10^{-18} \mathrm{~cm}^{2}$ and is useful for retrieving $\mathrm{SO}_{2}$ concentration from absorption measurements. Fluorescence from this state, however, is extremely weak due to the long natural fluorescence lifetime compared to fast collisional quenching into the triplet and ground states. A series of stronger features extending from $\sim 170$ to $235 \mathrm{~nm}$ has been assigned to the $\widetilde{\mathrm{C}}\left({ }^{1} \mathrm{~B}_{2}\right) \leftarrow \widetilde{\mathrm{X}}\left({ }^{1} \mathrm{~A}_{1}\right)$ transition, despite some confusion in the early literature where these transitions were assigned to both $\widetilde{\mathrm{C}}$ and $\widetilde{\mathrm{D}}$ states (e.g., Brand and Srikameswaran, 1972; Hui and Rice, 1973). The maximum absorption observed for $\widetilde{\mathrm{C}}\left({ }^{1} \mathrm{~B}_{2}\right) \leftarrow \widetilde{\mathrm{X}}\left({ }^{1} \mathrm{~A}_{1}\right)$ of $1.5 \times 10^{-17} \mathrm{~cm}^{2}$ occurs $\sim 35 \mathrm{~nm}$ below than the $0-0$ transition at $235 \mathrm{~nm}$, evidence of the Franck-Condon offset between the $\widetilde{X}$ and $\widetilde{C}$ states. Consequently, fluorescence from the $\widetilde{\mathrm{C}}$ state to the $\widetilde{\mathrm{X}}$ state is significantly red-shifted relative to the excitation wavelength and spans $\sim 100 \mathrm{~nm}$ (Fig. 2).

The photoexcited fluorescence from the $\widetilde{\mathrm{C}}$ state has been studied in detail by Okabe (1971), Hui and Rice (1973) and Ahmed and Kumar (1992). A dominant feature in the spectrum results from a predissociation threshold near $218.7 \mathrm{~nm}$ (Bludský et al., 2000). At wavelengths longer than this threshold, the zero-pressure limit fluorescence quantum yield is greater than 0.8 and fluorescence lifetimes are as long as $320 \mathrm{~ns}$, while at shorter wavelengths the yield quickly drops below 0.1 due to rapid dissociation dominating the fate of the excited molecule and the fluorescence lifetime is close to $30 \mathrm{~ns}$ (Hui and Rice, 1973). Due to the competing factors of absorption cross section, predissociation and fluorescence lifetimes, it is expected that at $10-100 \mathrm{hPa}$ the highest LIF signal could be obtained with excitation near $220.6 \mathrm{~nm}$.

The choice of excitation wavelength in the present work has been somewhat determined by the availability of suitable laser technology. We use the fifth harmonic of a tunable fiber-amplified diode laser at $1084.5 \mathrm{~nm}$, to pump the $\mathrm{SO}_{2}$ excitation at $216.9 \mathrm{~nm}$. Based on the published high-resolution $\mathrm{SO}_{2}$ absorption cross section and fluorescence quantum yield data, we estimate that the achievable signal level at $216.9 \mathrm{~nm}$ is $\sim 54 \%$ of that achievable at the optimum pumping wavelength of $220.6 \mathrm{~nm}$. An advantage of 216.9 is that an online/ offline extinction ratio of $>10$ is expected for $<6 \mathrm{pm}$ of laser tuning.

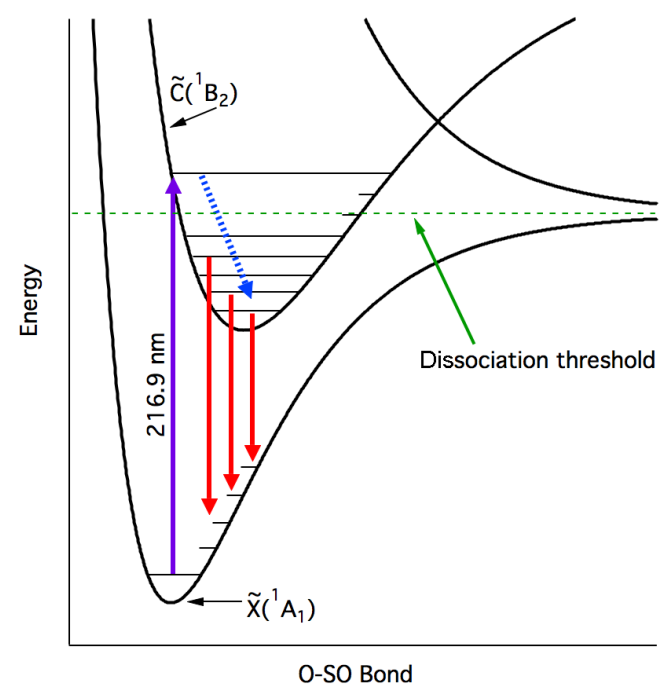

Figure 2. Schematic of the relevant $\mathrm{SO}_{2}$ electronic structure and LIF process. Excitation from the ground state, $\widetilde{\mathrm{X}}$, to above the dissociation threshold in the $\widetilde{\mathrm{C}}$ state at $216.9 \mathrm{~nm}$ (purple line) leads to predissociation in the majority of $\mathrm{SO}_{2}$ molecules. A small fraction undergo internal vibrational relaxation (dashed blue arrow) followed by red-shifted fluorescence (red arrows).

\subsection{Laser subsystem}

The concept of the laser system is to fiber-amplify infrared pulses from a tunable narrow-linewidth laser and then generate UV light from the pulses using a series of nonlinear crystals. A similar approach has been implemented to measure atmospheric formaldehyde $\left(\mathrm{CH}_{2} \mathrm{O}\right)$ using LIF at $353 \mathrm{~nm}$ excitation (Cazorla et al., 2015; DiGangi et al., 2011). The advantages of fiber-amplifier-based systems over the more traditional dye or Ti : sapphire-based UV laser systems include significantly reduced size, weight and power requirements, and significant reductions in the sensitivity of the laser to the vibration and temperature environment of operation. These advantages make routine atmospheric field measurements, including aircraft operation, much more attractive than with prior technologies.

The fiber amplification is achieved using $\mathrm{Yb}^{3+}$-doped optical fibers. In these fibers a population inversion can be pumped most efficiently at $976 \mathrm{~nm}$, and broad stimulated emission ranging from $\sim 1000 \mathrm{~nm}$ to over $1100 \mathrm{~nm}$ can be achieved. Two primary challenges distinguish this work from prior fiber-laser-based atmospheric LIF measurements: (1) currently the required lasers are not commercially available, and (2) the scheme for generating $216.9 \mathrm{~nm}$ relies on $\mu \mathrm{J}$ level pulse energies at $1084.5 \mathrm{~nm}$, which has a significantly lower $\mathrm{Yb}^{3+}$ emission cross section than the $1059 \mathrm{~nm}$ used for $\mathrm{CH}_{2} \mathrm{O}$ (peak $\mathrm{Yb}^{3+}$ emission is near $1030 \mathrm{~nm}$ ), which makes it harder to achieve the required total gain. Here, these issues were overcome by building a custom laser in-house. A two-stage fiber amplifier was constructed that consists of a 


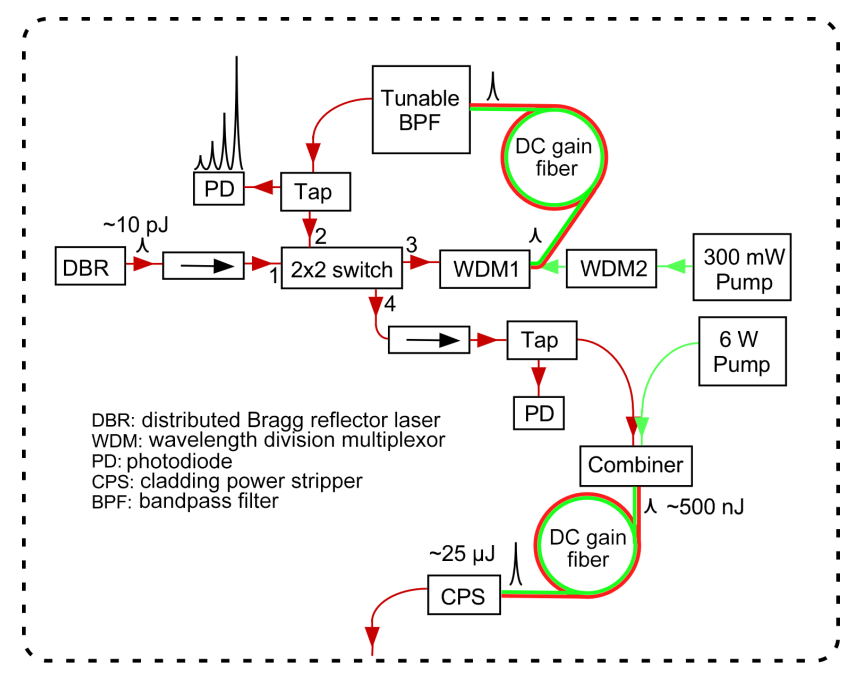

Figure 3. Schematic of the fiber-amplified diode laser system at $1084.5 \mathrm{~nm}$. See text in Sect. 2.2 for detailed explanation.

regenerative preamplifier followed by a double-clad power amplifier.

A schematic of the custom fiber laser is shown in Fig. 3. All components of the fiber amplifier are hermetic and factory-fiber-coupled using polarization-maintaining fibers. A temperature-tuned distributed Bragg reflector (DBR) laser (Photodigm) is pulsed with $\sim 2 \mathrm{~ns}$ current pulses at $25 \mathrm{kHz}$ using a short-pulse laser driver (Highland Technology) providing pulse energies of $\sim 10 \mathrm{pJ}$ with 2 ns duration. Pulses immediately pass through a $70 \mathrm{~dB}$ isolator to protect the DBR against feedback from the amplifier.

To maximize gain and suppress amplified spontaneous emission (ASE) in the preamplifier, a regenerative amplifier was constructed. This allows a pulse to pass through the same gain fiber loop a large number of times with the number of passes being controlled using software. A $2 \times 2$ optoceramic-based switch (Boston Applied Technology Inc.) was used to leak a seed pulse from the DBR laser into the amplifier loop and control the number of passes. Normally, port 1 is connected to port 3 , and port 2 is connected to port 4 (see Fig. 3). In this state a pulse is able to enter the amplifier loop and pass through the first wavelength division multiplexer (WDM1), where it combines with $976 \mathrm{~nm}$ light from a wavelength-stabilized $300 \mathrm{~mW}$ laser diode (Oclaro). As shown in Fig. 3, an additional WDM filter was used to protect the $976 \mathrm{~nm}$ pump diode from feedback in the regenerative amplifier. After WDM1, the pulse passes through $8 \mathrm{~m}$ of highly Yb-doped single-clad gain fiber (Nufern). A tunable bandpass filter (BPF, Agiltron) with a $-3 \mathrm{~dB}$ bandwidth of $1 \mathrm{~nm}$ removes most of the broadband ASE, which peaks near $1030 \mathrm{~nm}$. A $1 \%$ optical tap is used to monitor the light inside the regenerative amplifier. The pulse then returns to port 2 on the switch. If the switch is energized at this point, ports 2 and 3 will be connected, allowing the pulse to make another pass through the amplifier. Due to the length of the fibers in the amplifier, a single pass through the regenerative amplifier loop takes $70 \mathrm{~ns}$, meaning that with the amplifier running at $25 \mathrm{kHz}$ as many as 570 passes through the amplifier are possible. Typically it is found that about 15 passes are optimal and additional passes only lead to a reduction in pulse energy due to amplifier component losses. When the pulse has made the optimum number of passes, the switch is de-energized and the pulse exits through port 4 . The maximum pulse amplitude achievable with the regenerative amplifier was observed to be somewhat insensitive to the input pulse energy. This suggests that the output of the amplifier may be limited by a nonlinear effect in one of the components (perhaps in the switch). Typically $\sim 1 \mu \mathrm{J}$ pulse energy ( $\sim 0.5 \mathrm{~kW}$ peak power) was achieved.

After exiting the regenerative amplifier, pulses pass through a $45 \mathrm{~dB}, 10 \mathrm{~W}$ handling isolator, through another $1 \%$ tap and into a multimode signal-pump combiner. Here, the single-clad PM fiber is fused to a double-clad PM fiber, and the output from a $6 \mathrm{~W}$ wavelength-stabilized $976 \mathrm{~nm}$ multimode laser diode (Innovative Photonic Solutions) is coupled into the first cladding of the fiber. The combiner output is fused to a $5 \mathrm{~m}$ section of $15 / 130$ double-clad Yb-doped fiber (Nufern). After the gain fiber, a cladding power stripper is used to remove the residual $976 \mathrm{~nm}$ pump light.

All of the above components are housed inside a hermetically sealed aluminum enclosure maintained at a pressure of $\sim 1$ bar to prevent overheating of any components during operation at high altitude. The final output fiber passes through a fitting in the enclosure wall to which it is epoxied to provide a seal. The output end of the fiber is end capped with a $600 \mu \mathrm{m}$ core-free fiber to allow the beam to expand to $\sim 100 \mu \mathrm{m}$ prior to exiting the fiber in order to avoid optical damage. Typically, the $2 \mathrm{~ns}$ pulses exit the fiber with $\sim 25 \mu \mathrm{J}$ energy ( $\sim 12.5 \mathrm{~kW}$ peak power), achieving a net gain of approximately $64 \mathrm{~dB}$. Average power at $25 \mathrm{kHz}$ pulse rate is approximately $600 \mathrm{~mW}$.

After exiting the fiber, the free space beam is collimated to a diameter of $300 \mu \mathrm{m}$ and passes a number of passive elements to generate $216.9 \mathrm{~nm}$ with a conversion efficiency of $\sim 0.5 \%$. Figure 4 shows a schematic of the free-space beam path. The scheme used is identical to that reported by Koplow et al. (2002). A zero-order half-wave plate controls the polarization of the fundamental before it passes through a type-II phase-matched potassium titanyl phosphate (KTP) crystal $(3 \times 3 \times 10 \mathrm{~mm})$ to generate the second harmonic. The $542.3 \mathrm{~nm}$ light produced is combined with the residual $1084.5 \mathrm{~nm}$ in a type-I phase-matched lithium triborate $(\mathrm{LBO})$ crystal $(3 \times 3 \times 10 \mathrm{~mm})$ to generate the third harmonic $(361.5 \mathrm{~nm})$. A custom wave plate $(\lambda / 2 @ 542.3 \mathrm{~nm}$, $\lambda$ @ $361.5 \mathrm{~nm}$ ) then rotates the residual $542.3 \mathrm{~nm}$ to be parallel to the $361.5 \mathrm{~nm}$. Then the beam passes through an $f=40 \mathrm{~mm}$ lens to focus the beams slightly into a type-I phase-matched beta barium borate (BBO) crystal $(3 \times 5 \times 20 \mathrm{~mm})$ to generate the fifth harmonic at $216.9 \mathrm{~nm}$. 


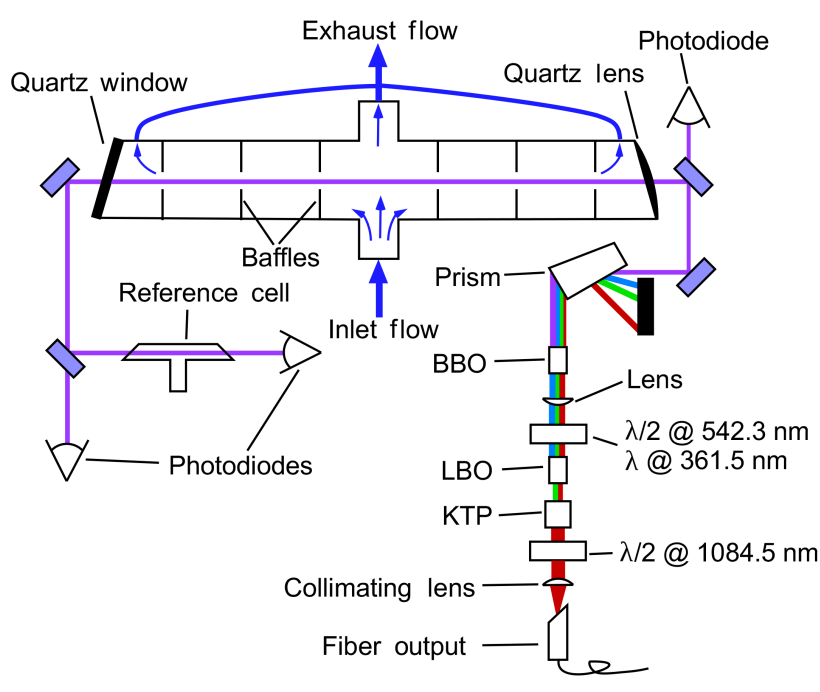

Figure 4. Schematic of the free-space optical setup.

A Pellin-Broca prism separates the harmonics, and all but the $216.9 \mathrm{~nm}$ are dumped into a beam block. The laser power achieved at $216.9 \mathrm{~nm}$ is sensitive to many parameters, such as the pulse energy and duration at $1084.5 \mathrm{~nm}$ (itself sensitive to many operating parameters of the fiber laser system), and the alignment and temperature of the nonlinear crystals. Typically, during laboratory and flight operation we observed power in the range of 2-4 $\mathrm{mW}$.

Laser tuning is achieved by modulating the temperature of the seed DBR laser. The DBR tuning rate is $70 \mathrm{pm}^{\circ} \mathrm{C}^{-1}$, and therefore the tuning rate for the fifth harmonic at $216.9 \mathrm{~nm}$ is $14 \mathrm{pm}^{\circ} \mathrm{C}^{-1}$. As the laser temperature can be controlled to better than $0.005^{\circ} \mathrm{C}$, the wavelength precision by temperature tuning is $<0.07 \mathrm{pm}$, which is sufficient to resolve the Doppler linewidth of $\mathrm{SO}_{2}(\sim 0.3 \mathrm{pm}$ at $298 \mathrm{~K})$.

\subsection{Optics bench}

The key elements of the optical detection system are shown in Fig. 4. All components are mounted on a $40 \times 55 \times 1.5 \mathrm{~cm}$ carbon fiber plate with stainless-steel inserts (CarbonVision $\mathrm{GmbH})$. The nonlinear optical components are mounted on a $9.5 \mathrm{~mm}$ thick temperature stabilized aluminum plate. The plate and prism are surrounded by optical black-anodized aluminum sheeting to reduce eye hazard and insulated with Nomex to keep the optics at a near-constant temperature during flight operation on the WB-57F. The $216.9 \mathrm{~nm}$ beam exits the enclosure through a small hole and is steered by dielectric mirrors for a single pass through the LIF cell. The LIF cell design is nearly identical to that reported by Cazorla et al. (2015). Background from scatter is reduced in the cell using a series of baffles with $3 \mathrm{~mm}$ diameter holes for the beam to pass through. The baffles closest to the interrogation volume are coated with a black carbon-nanotube coating. Inside the cell a lens collects a fraction of the fluorescence and scat- ter, and these photons pass through a filter stack before being imaged onto the photocathode of a photomultiplier tube module (PMT, Hamamatsu H10721-210). A concave mirror located opposite the collection optic increases the signal by $\sim 50 \%$ by increasing the solid angle imaged onto the PMT. The filter stack consists of dielectric $250 \mathrm{~nm}$ long-pass and $240-400 \mathrm{~nm}$ bandpass filters (Asahi) and a colored glass bandpass filter (Schott UG5). After exiting the cell, the laser beam is steered with two more mirrors through a sealed $\mathrm{SO}_{2}$ reference cell. Transmission through the cell is determined using two amplified photodiodes, one measuring the $\sim 5 \%$ leakage through the final steering mirror and the other measuring the residual beam after passing through the reference cell. The reference cell contains $0.4 \mathrm{hPa} \mathrm{SO} 2$ and $35 \mathrm{hPa} \mathrm{N} 2$ with a length of $5 \mathrm{~cm}$ for an optical depth of about $20 \%$ at the $\mathrm{SO}_{2}$ absorption maximum, allowing for high-precision measurements of the relative absorption. The cell is used to verify that the maximum absorption and fluorescence feature are located during periodic spectral scans of the laser.

The signal from the PMT is analyzed using a $50 \mathrm{MHz}$ pulse amplifier-discriminator module (PAD) for singlephoton counting. Rising edges from the PAD that arrive during a $20 \mathrm{~ns}$ gate following the laser pulse are counted using a $200 \mathrm{MHz}$ digitizer. All timing control in this system is accomplished using a single National Instruments cRIO computer system. The cRIO runs a field-programmable gate array at $200 \mathrm{MHz}$ that interacts with the laser system and PAD through an integrated digital I/O module, thereby providing $5 \mathrm{~ns}$ precision in controlling timing between events. This system controls (1) timing of the seed laser shots, (2) regenerative amplifier gates and (3) photon counting and gating.

\subsection{Linearity}

The fluorescence lifetime of $\mathrm{SO}_{2}$ when pumped at $216.9 \mathrm{~nm}$ is short compared to the pulse-pair resolution of the photoncounting system, which is limited to $\sim 30 \mathrm{~ns}$ by the pulse duration from the PAD. By adjusting the delay between the excitation laser pulse and photon-counting gates in $5 \mathrm{~ns}$ increments, we estimate that the e-folding lifetime of the fluorescence signal in our system when operated at $50 \mathrm{hPa}$ is $4 \mathrm{~ns}$. Using the previously reported rate coefficients for radiative $\left(k_{\mathrm{r}}=0.74 \times 10^{7} \mathrm{~s}^{-1}\right)$ and non-radiative $\left(k_{\mathrm{nr}}=9.643 \times 10^{7}\right.$ $\mathrm{s}^{-1}$ ) relaxation of $\mathrm{SO}_{2}$ when excited at $216.9 \mathrm{~nm}$ (Hui and Rice, 1973) and for quenching by argon $\left(k_{\mathrm{q}}=5.2 \times 10^{-11}\right.$ molecule ${ }^{-1} \mathrm{~cm}^{3} \mathrm{~s}^{-1}$ ) (Okabe, 1971), a fluorescence lifetime at $50 \mathrm{hPa}(35 \mathrm{hPa})$ of $5.9 \mathrm{~ns}(6.7 \mathrm{~ns})$ is calculated. This is in reasonable agreement with our observation of $4 \mathrm{~ns}$, and the difference is likely due to the more efficient quenching of $\mathrm{SO}_{2}^{*}$ by air than by argon. Because the laser pulse $(\sim 2 \mathrm{~ns})$ is also much shorter than the pulse-pair resolution, this means that for each laser shot our system will count at most one photon. This was verified by saturating the detection system with fluorescent photons by sampling a flow containing $\sim 100 \mathrm{ppb}$ of $\mathrm{SO}_{2}$ at $35 \mathrm{hPa}$ with $4 \mathrm{~mW}$ laser power (sensitivity $\sim 14$ 
counts per second (cps) $\mathrm{ppt}^{-1}$; see Section 2.5 and Fig. 6) and observing a resultant count rate exactly equal to the laser repetition rate of $25 \mathrm{kHz}$, even though the expected rate of fluorescent photons incident on the detector is $1400 \mathrm{kHz}$.

In prior works (Bradshaw et al., 1982; Matsumi et al., 2005) where $10 \mathrm{~Hz}$ lasers with much higher pulse energies were used, such that the typical rate of photons arriving at the detector is much higher than the laser repetition rate, single-photon counting was precluded and noisier analog signal conditioning electronic systems were required. In the present system, single-photon counting is possible, but the instrument response becomes noticeably nonlinear when the signal rate becomes a significant fraction of the laser repetition rate. With the typical background $(300 \mathrm{cps})$ and signal $\left(7 \mathrm{cps} \mathrm{ppt}^{-1}\right)$ levels observed this was only important for relatively high ( $>1 \mathrm{ppb}) \mathrm{SO}_{2}$ mixing ratios.

The relationship between the observed and true photon count rates can be accounted for during data reduction in an exact way, resulting in no additional uncertainties in the instrument response function. As discussed previously (Wennberg et al., 1994), the observed $(O)$ and true $(T)$ count rates are related by the expression

$T=-f \ln \left(1-\frac{O}{f}\right)$,

where $f$ is the laser repetition rate. Figure 5 shows the calculated relationship between the true rate of photons hitting the detector and the observed count rate given the laser repetition rate of $25 \mathrm{kHz}$, and the maximum count rate is equal to the laser repetition rate. The accuracy of the correction due to applying Eq. (1) is verified during instrument calibrations (e.g., Fig. 6). At very high count rates, the precision of the $\mathrm{SO}_{2}$ measurement is degraded because only a fraction of the signal photons are counted, thereby limiting the dynamic range of the instrument. For example, at an observed count rate near $99.7 \%$ of the maximum count rate (24925 CPS or $20.5 \mathrm{ppb}$ ) the increase in $\mathrm{SO}_{2}$ required to result in one additional expected PMT count is equal to the precision due to Poisson statistics (55 ppt). Therefore, we typically use the data when the observed count rate is less than $90 \%$ of the laser repetition rate, eliminating additional uncertainties due to this issue. At this signal level the increase in the observed count rate for each additional 10 photons is 1 count, and the noise due to Poisson statistics is much greater than the precision degradation due to applying Eq. (1). During the initial deployment of the instrument on the WB-57F, this never resulted in data loss as the highest mixing ratio observed was $3.1 \mathrm{ppb}$. During operation in more polluted environments the upper limit of detection can be extended by reducing the laser power or tuning the laser to a less strong absorption feature of $\mathrm{SO}_{2}$.

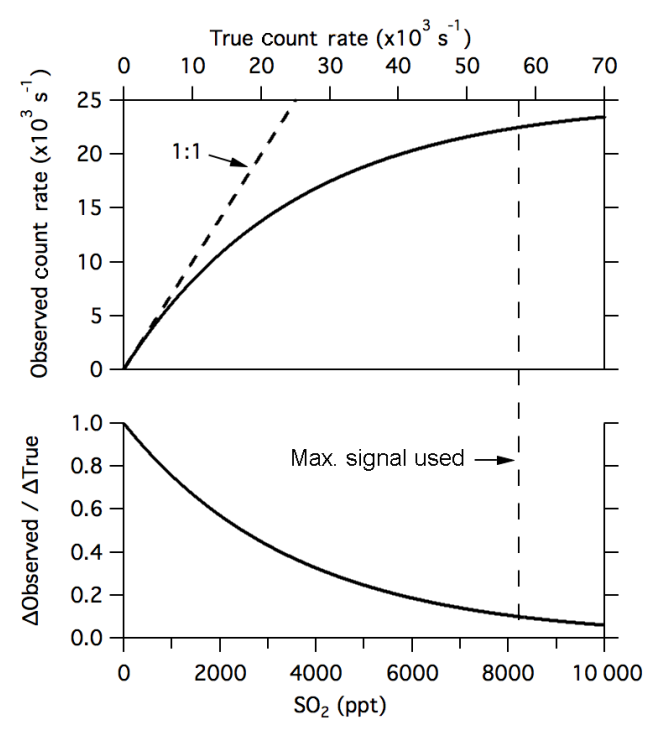

Figure 5. Count rate linearity adjustment. (Top) Calculated relationship between observed and true photon count rates from Eq. (1) assuming a $25 \mathrm{kHz}$ laser pulse frequency and a maximum of 1 count/laser pulse. (Bottom) Fraction of increased signal observed as a function of the true count rate. Bottom axis shows the $\mathrm{SO}_{2}$ mixing ratio assuming $300=\mathrm{CPS}$ background and $7 \mathrm{CPS} \mathrm{ppt}{ }^{-1} \mathrm{SO}_{2}$.

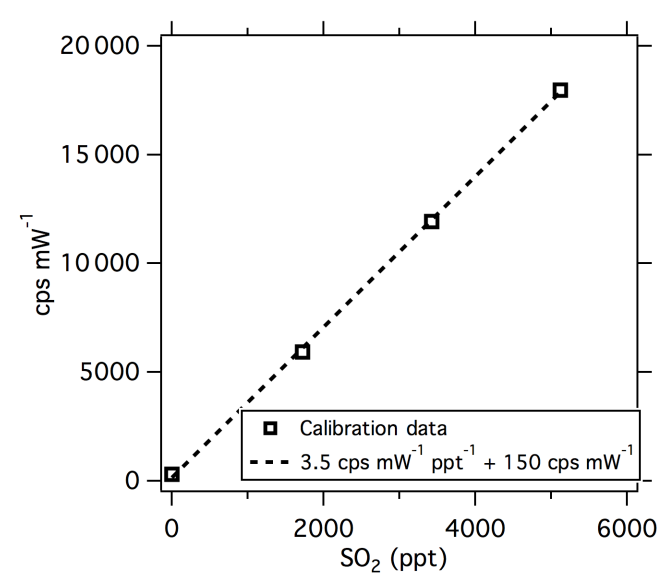

Figure 6. Example in-flight $\mathrm{SO}_{2}$ calibration during the flight of 28 October 2015. Data shown are the linearized count rate divided by the measured laser power. The dashed line shows a fit to the four data points indicating the sensitivity of $3.5 \mathrm{cps} \mathrm{mW}^{-1} \mathrm{ppt}^{-1}$ and background of $150 \mathrm{cps} \mathrm{mW}^{-1}$.

\subsection{Sampling and calibration system}

Figure 7 shows a schematic of the sampling and calibration system used on the WB-57F aircraft. The sampling system for the instrument uses two custom butterfly valves (Gao et al., 1999) to maintain constant mass flow and cell pressure during operation throughout the altitude range of the aircraft. All tubing and fittings in the sample and calibration lines are constructed of either Teflon PFA (perfluoroalkoxy alkane) 


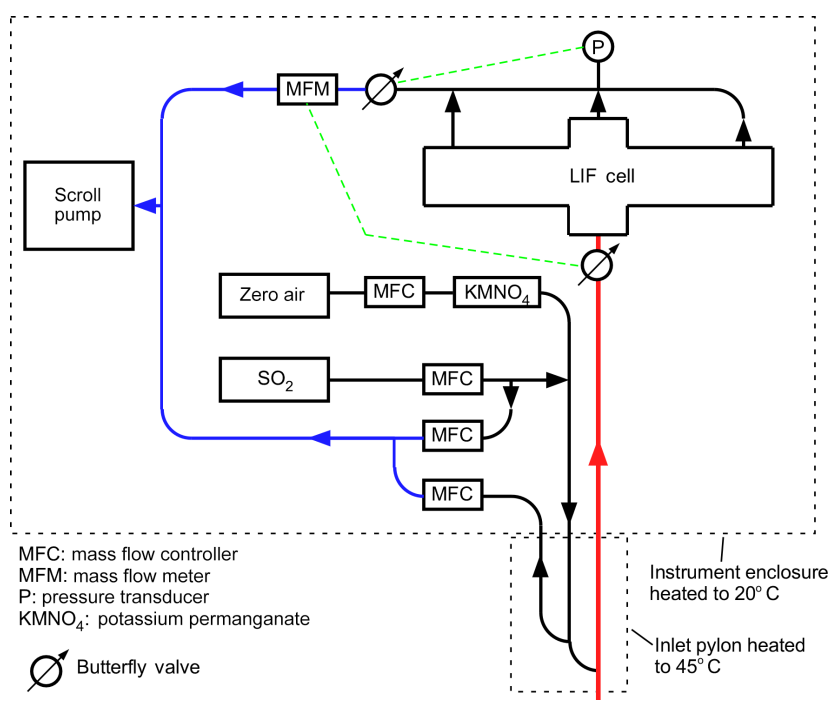

Figure 7. Schematic of flow and calibration system. Red line indicates the main inlet, which was housed in a pylon extending 28 $\mathrm{cm}$ below the WB-57F skin and heated to $45^{\circ} \mathrm{C}$. Blue lines indicate components at vacuum $(<10 \mathrm{hPa})$. Excluding the components in the inlet pylon, all instrument components were housed in an insulated enclosure maintained at $20-30{ }^{\circ} \mathrm{C}$.

or PEEK (polyetheretherketone) material, save one stainlesssteel fitting connecting the sample line to the LIF cell.

Air is drawn through a $6.3 \mathrm{~mm}$ inner-diameter PFA tube that extends $28 \mathrm{~cm}$ below the WB-57F skin and is housed in an airfoil structure. The inlet opening is oriented perpendicular to the direction of airflow around the aircraft, eliminating super-micron particles from the sample flow at WB57F flight speeds. A PFA tee in the sample line, located $5 \mathrm{~cm}$ from the inlet tip, is used to add zero and/or calibration gases to the inlet. Tubing and fittings housed inside the airfoil are temperature-controlled to $45^{\circ} \mathrm{C}$. Inside the heated main instrument enclosure, the sample passes through a custom butterfly valve similar to that described by Gao et al. (1999) constructed of PEEK material with a PFA vane before entering the LIF cell. The majority of the sample flow $(\sim 1500 \mathrm{sccm})$ exits through the primary cell exhaust (see Fig. 4) opposite the inlet, and about $250 \mathrm{sccm}$ are drawn through each of the LIF cell arms to eliminate dead volume in the analysis region. The cell exhaust passes through a second butterfly valve and then to a $160 \mathrm{~L} \mathrm{~min}^{-1}$ scroll pump.

The inlet butterfly valve is servo-controlled to a mass flow meter on the cell exhaust line to maintain the sample flow at $2000 \pm 30 \mathrm{sccm}$ during flight operation. The exhaust butterfly valve is servo-controlled to a pressure transducer (MKS Baratron) located at the LIF cell exhaust to maintain the cell pressure to a constant value during flight to eliminate fluctuations in LIF sensitivity. The operation cell pressure chosen is typically the highest pressure that can be maintained throughout flight without suffering reductions in the flow rate at the highest flight altitudes. On the WB-57F, with ambi- ent pressure as low as $80 \mathrm{hPa}$, the cell pressure was set to $35 \mathrm{hPa}$, which was maintained by the servo-control system to $\pm 0.3 \mathrm{hPa}$. Laboratory tests showed that the signal up to $100 \mathrm{hPa}$ was nearly linear in pressure, resulting in an error in $\mathrm{SO}_{2}$ of less than $1 \%$ due to the $35 \pm 0.3 \mathrm{hPa}$ pressure control.

The calibration system uses a compressed gas standard of $\mathrm{SO}_{2}$ in air (Scott Marrin), typically near $5.0 \mathrm{ppm}$ with $\pm 2 \%$ uncertainty. The accuracy of this standard is verified before and after flight series by comparison to a suite of similar standards in our laboratory. An all-stainless-steel regulator and mass flow controller (Alicat MCS series) handle delivery of the $\mathrm{SO}_{2}$ calibration standard. At takeoff a constant $2 \mathrm{sccm}$ flow of $\mathrm{SO}_{2}$ through the calibration tubing is initiated and maintained throughout flight, except for changes during calibration sequences. During calibrations, the small flow (1$10 \mathrm{sccm}$ ) of the $\mathrm{SO}_{2}$ standard is mixed with $2500-3000 \mathrm{sccm}$ of zero air (Scott Marrin) that has passed through a potassium permanganate desiccant cartridge to eliminate any remaining $\mathrm{SO}_{2}$. This approach can provide calibration mixing ratios in the LIF cell in the range of 1.7-20 $\mathrm{ppb} \mathrm{SO}_{2}$. Typically, a calibration sequence of three nonzero $\mathrm{SO}_{2}$ mixing ratios and one zero-air zero is performed every hour during flight operation. Figure 6 shows data from one calibration from the flight on October 28, 2015. The data in Fig. 6 have been linearized by applying Eq. (1).

When calibration gas is not being added to the sample line, the $2 \mathrm{sccm}$ of gas standard is returned to the vacuum pump through a low-pressure-drop mass flow controller (Bronkhorst) with a small excess return flow so as to eliminate contamination of the zero-air line. Similarly, when zero air is not being delivered to the inlet, a small zero-air flow of $\sim 25 \mathrm{sccm}$ continuously flows through the zero-air line to near the addition point at the inlet and then is diverted to the vacuum pump using a mass flow controller with a small excess flow to eliminate dilution of the sample flow.

No evidence of artifacts due to sampling hysteresis is apparent from the flight data. A conservative evaluation of the sampling system total response time (the time required to observe an instantaneous change in the sampled $\mathrm{SO}_{2}$ mixing ratio) can be made from the data collected at the end of calibration sequences. Figure 8 shows one such example, when the $\mathrm{SO}_{2}$ return mass flow controller is opened to end an $\mathrm{SO}_{2}$ calibration event. A fit to the observed signal decrease from $2.2 \mathrm{ppb}$ to 0 yields an e-folding time of $0.10 \mathrm{~s}$. This indicates that the $5 \mathrm{~Hz}$ data collection rate is well matched to the response time of the sampling system.

\subsection{Instrument response and data reduction}

The instrument response $\left(\mathrm{cps} \mathrm{mW}^{-1}\right)$ is defined as the linearized count rate (Eq. (1) applied to the observed count rate) normalized by the measured laser power. In principle, this response level is due to the sum of a relatively stable background and a signal that varies with the concentrations of fluorescent species in the sampled air. 


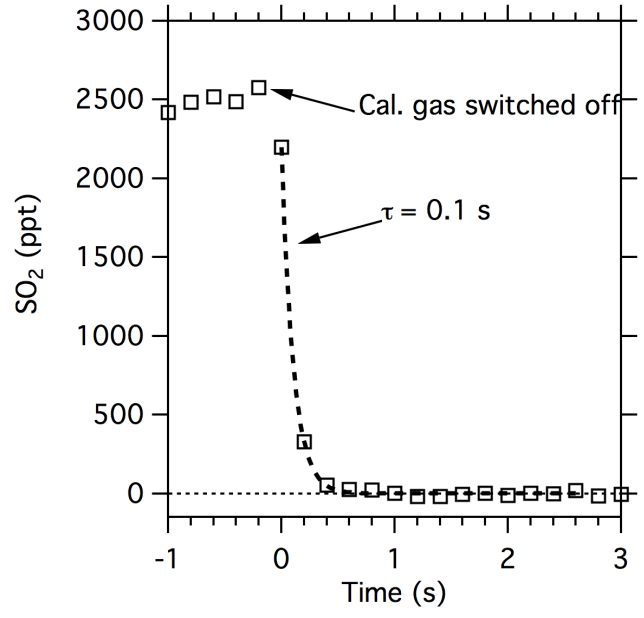

Figure 8. Example of the instrument time response following the removal of calibration gas from the instrument sample line. The dashed line is an exponential decay with a time constant of $0.1 \mathrm{~s}$.

The background in the instrument as it is currently configured (150-250 $\mathrm{cps} \mathrm{mW}^{-1}$ when sampling zero air) appears to be almost entirely due to the interactions of the laser with the sample cell and/or optics, as evidenced by the insensitivity of this background to sample pressure. The PMT dark count rate at a duty cycle of 1 would be $\sim 50 \mathrm{cps}$. However, the signal gating $(20 \mathrm{~ns}$ at $25 \mathrm{kHz})$ yields a duty cycle of $5 \times 10^{-4}$, resulting in an expected dark count rate $0.025 \mathrm{cps}$. A series of tests with varying filter stacks in front of the PMT suggest that the spectrum of the existing background is similar to that of the signal, leading to the conclusion that fluorescence of an optic or the cell itself is the source of these photons.

The signal $S\left(\mathrm{cps} \mathrm{mW}{ }^{-1}\right.$ ) resulting from $\mathrm{SO}_{2}$ in the LIF cell is equal to the product of the excitation rate for producing electronically excited $\mathrm{SO}_{2}, E(\lambda)\left(\mathrm{SO}_{2}^{*} \mathrm{~s}^{-1} \mathrm{~mW}^{-1}\right)$, the fluorescence quantum efficiency, $\phi$ (photons emitted $\mathrm{SO}_{2}^{*-1}$ ) and a dimensionless factor $\Omega$ (fluorescent photon counts per photons emitted) that includes the geometric and spectroscopic (filters and PMT response function) collection efficiencies.

$S(\lambda)=E(\lambda) \cdot \varphi \cdot \Omega$

All three quantities are to some degree dependent on the wavelength $(\lambda)$ of the excitation laser, but over the small changes in $\lambda$ relevant to this system the variations in $E$ overwhelmingly dominate the observed variations in $S$, and therefore we only consider the wavelength dependence of $E$. In the optically thin regime where the incident laser power is independent of the $\mathrm{SO}_{2}$ mixing ratio (as is the case here), $E$ is linearly proportional to the $\mathrm{SO}_{2}$ mixing ratio and to the convolution of the $\mathrm{SO}_{2}$ absorption cross section with the laser spectrum.

The fluorescence quantum efficiency of the excited $\mathrm{SO}_{2}^{*}$ molecules is determined by the competition between fluorescence $\left(k_{\mathrm{r}}\right)$ against non-radiative unimolecular relaxation $\left(k_{\mathrm{nr}}\right)$ and bimolecular quenching $\left(k_{\mathrm{q}}\right)$. Using the values of $k_{\mathrm{r}}, k_{\mathrm{nr}}$ and $k_{\mathrm{q}}$ stated above at $35 \mathrm{hPa}$ and $300 \mathrm{~K}$, values of $\tau_{\mathrm{r}}=135 \mathrm{~ns}, \tau_{\mathrm{nr}}=10 \mathrm{~ns}$, and $\tau_{\mathrm{q}}=23 \mathrm{~ns}$ are calculated. Thus, the fate of $\mathrm{SO}_{2}^{*}$ when excited at $216.9 \mathrm{~nm}$ is primarily nonradiative dissociation of the molecule. Since $k_{\mathrm{q}}$ is also short relative to $\tau_{\mathrm{r}}$, variations in $k_{\mathrm{q}}$ with the composition of the air might lead to significant variations in the value of $\phi$. In the atmosphere, the only species which might be expected to have a concentration variable enough to affect the value of $\phi$ would be water vapor. Bradshaw et al. (1982) showed that in their $\mathrm{SO}_{2}$ LIF system with excitation at $222 \mathrm{~nm}$, the fluorescence quantum yield in dry air was indistinguishable from that of air with an $\mathrm{H}_{2} \mathrm{O}$ mixing ratio of $17 \times 10^{3} \mathrm{ppm}$. It is expected that the effect of any variations in quenching efficiency would result in even smaller changes in $\phi$ in the present system because $k_{\mathrm{nr}}$ when pumped at $216.9 \mathrm{~nm}$ is more than 15 times greater than $k_{\mathrm{nr}}$ following $222 \mathrm{~nm}$ pumping. We tested our system and observed that the sensitivity at a water vapor mixing ratio of $12 \times 10^{3} \mathrm{ppm}$ was indistinguishable $\left(<2 \%\right.$ different) from that at $10 \mathrm{ppm} \mathrm{H}_{2} \mathrm{O}$. This is an $\mathrm{H}_{2} \mathrm{O}$ mixing ratio at least two orders of magnitude higher than any that would be encountered in the UT-LS. Therefore, we assume any effect of quenching by $\mathrm{H}_{2} \mathrm{O}$ is negligible and calibrate the instrument in dry air.

The LIF technique is specific not only to the absorption spectrum of $\mathrm{SO}_{2}$ but also to the red-shifted emission spectrum that is selected by the filter stack, as well as to the fluorescence timing that is gated by the digitizer. However, photon counts could also possibly result from fluorescence of species other than $\mathrm{SO}_{2}$ in the sample cell. The only atmospheric compounds expected to possibly result in spurious fluorescence in this system are aromatic compounds. Some of these species, especially polycyclic aromatic compounds have high and relatively continuous absorption cross sections in this region of the UV. For example, naphthalene and xylene compounds have absorption cross sections at $216.9 \mathrm{~nm}$ that are comparable to that of $\mathrm{SO}_{2}$. Because these molecules lack the fine spectral structure of $\mathrm{SO}_{2}$, the presence of these compounds would result only in an increase in the background in this instrument. These aromatic species are typically one order of magnitude more reactive with $\mathrm{OH}$ than is $\mathrm{SO}_{2}$ and are therefore concentrated in the boundary layer and are not expected to be present in measurable quantities in the UT-LS region.

The photon collection efficiency term $\Omega$ is independent of the composition of the sample gas. Therefore, $S(\lambda)$ in Eq. (2) can be reduced to the product of the $\mathrm{SO}_{2}$ mixing ratio $c$ and a single factor $\alpha(\lambda)\left(\mathrm{cps} \mathrm{mW}^{-1} \mathrm{ppt}^{-1}\right)$ that is determined empirically using a calibration standard. Typical values of $\alpha(\lambda)$ at $\lambda=216.9 \mathrm{~nm}$ in the current instrument configuration are in the range of $2-4 \mathrm{cps} \mathrm{mW}^{-1} \mathrm{ppt}^{-1}$. Figure 9 shows a comparison of measurements of $S(\lambda)$ with the highest resolution $\mathrm{SO}_{2}$ absorption cross section available in the literature. Figure 9 shows that the spectrum of the LIF signal follows that of the absorption cross section, but that the 


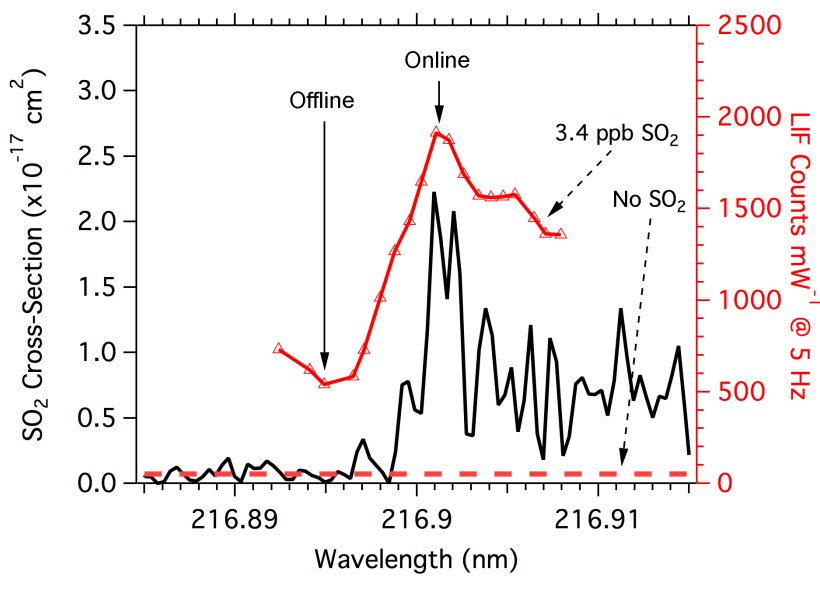

Figure 9. Example of observed signal during a scan of the laser when sampling $3.4 \mathrm{ppb} \mathrm{SO}_{2}$ from a gas standard during a WB-57F flight. The black line plotted on the left axis shows the literature $\mathrm{SO}_{2}$ absorption cross section. Plotted in red against the right axis is the observed signal from the LIF system. Red dashed line shows typical signal observed when scanning laser with a zero-air sample.

individual ro-vibronic $\mathrm{SO}_{2}$ features apparent in the absorption spectrum (narrow peaks in the black trace) do not appear in the fluorescence spectrum. This is likely because the linewidth of the laser used here is significantly wider than the natural linewidth of the absorption features. Although the linewidth of the DBR seed laser $(\sim 1 \mathrm{MHz})$ should in principle be significantly narrower than the individual $\mathrm{SO}_{2}$ lines $(2200 \mathrm{MHz})$, the process of pulsing the DBR current likely broadens the spectrum too much to resolve these lines. An advantage of the wider laser linewidth is that the LIF signal is not extremely sensitive to the precise location of the laser wavelength. A disadvantage is that the "offline" LIF signal, which is obtained by tuning the laser $\sim 6$ pm below the maximum signal wavelength, is significantly nonzero. Presumably, the "online" signal used for measurements is also somewhat lower than it would be if the laser linewidth were much narrower than the $\mathrm{SO}_{2}$ linewidth.

During engineering test flights we tested for the potential interference of fluorescent species other than $\mathrm{SO}_{2}$ by periodically temperature-tuning the laser to the online and offline excitation wavelengths (Fig. 9). Those data were reduced both by (1) using the online-offline difference as the $\mathrm{SO}_{2}$ signal and (2) using the difference between a zero-air zero and online as the $\mathrm{SO}_{2}$ signal. When reduced using both techniques, we observe no difference in the determined $\mathrm{SO}_{2}$ above the Houston boundary layer. In the current system where laser tuning is achieved by temperature modulation of the laser, the online-offline tuning results in a few seconds of lost data during the transition, thereby significantly reducing the $\mathrm{SO}_{2}$ measurement duty cycle. In addition, the precision is reduced by the aforementioned nonzero offline $\mathrm{SO}_{2}$ fluorescence. Therefore, during the VIRGAS science flights, measurements were performed with the laser wave- length maintained on the $\mathrm{SO}_{2}$ resonance near $216.9 \mathrm{~nm}$ and with regular zero-air additions were used to determine the instrument zero. Future work will focus on laboratory and ambient testing for interferences using a more rapidly currenttuned laser in order to make reliable measurements in the polluted boundary layer and free troposphere.

\section{WB-57F operation and performance}

During September and October 2015 a series of engineering and science flights were carried out with the $\mathrm{SO}_{2}$ instrument integrated on the NASA WB-57F based at Ellington Field and Harlingen, Texas. The $\mathrm{SO}_{2}$ instrument operated successfully during seven flights from 20 to 30 October up to $19.4 \mathrm{~km}$ altitude. In addition to the $\mathrm{SO}_{2}$ measurements, the in situ payload included instruments for measuring $\mathrm{O}_{3}(\mathrm{GaO}$ et al., 2012), water vapor and ice water content (Thornberry et al., 2015), meteorological parameters (Scott et al., 1990) and tracers (Heidt et al., 1989), thereby providing a valuable payload for investigating aspects of the UT-LS sulfur budget.

\subsection{Accuracy}

The typical operation of the $\mathrm{SO}_{2}$ instrument during the VIRGAS flights involved an hourly measurement cycle, with each hour including one four-point calibration of $\mathrm{SO}_{2}$ sensitivity (Fig. 6), three zero-air measurements and one wavelength scan of the laser (Fig. 9). Figure 10 shows a sample time series of the data during this hour cycle from the 29 October flight. The accuracy of the $\mathrm{SO}_{2}$ mixing ratios determined from the flight data is dependent on the accuracy of the zero levels and sensitivity factors $(\alpha)$ and the stability of these values between individual zero and sensitivity determinations.

The uncertainty in the $\mathrm{SO}_{2}$ calibration mixing ratio in the LIF cell is determined by the propagation of uncertainties in the calibration standard and the flows through the mass flow controllers used to dilute the standard in zero air. The $\pm 2 \%$ uncertainties in the two mass flow controllers (verified using a certified Bios DryCal flow standard) and in the $\mathrm{SO}_{2}$ calibration standard combine in quadrature to produce a $\pm 3.5 \%$ total uncertainty. The uncertainty in the slope derived from a fit of the calibration data (e.g., Fig. 6), which depends on the precision of the LIF count rate during calibration, was typically $\pm 1.5 \%$. These two terms sum to a $\pm 3.8 \%$ uncertainty in a single determination of the LIF sensitivity. Laboratory and in-flight testing during the initial deployment indicated slow apparent drift in the instrument sensitivity factors. Tests following the deployment demonstrated that this issue was primarily due to alignment issues with the photodiodes used to monitor the laser power. As a result, the measured sensitivity factors were interpolated linearly between hourly measurements. The variation in the calibration signal between successive hourly sensitivity measurements was on average $\pm 12 \%$. This apparent power drift is not believed to result in 

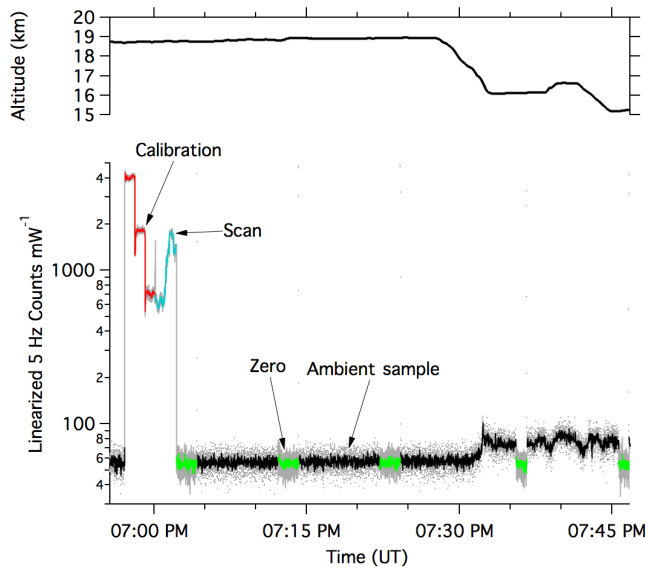

Figure 10. Data sample from flight on 27 October 2015. Top panel shows aircraft altitude, indicating a cruise in the lower stratosphere followed by descent into the upper troposphere. Bottom panel: gray dots show $5 \mathrm{~Hz}$ data. Black, red, cyan and green show $1 \mathrm{~Hz}$ averages of ambient sampling, calibration, laser wavelength scan and zero-air zeroing, respectively.

a significant error in the calculated $\mathrm{SO}_{2}$ because the same laser power measurement is used to normalize both the ambient and calibration $\mathrm{SO}_{2}$ signals. Nonetheless, as this drift is not fully understood and may have been somewhat due to drifts in the laser wavelength that cannot be corrected for at this time, we conservatively add the $\pm 12 \%$ and $\pm 3.8 \%$ to derive a total uncertainty of $\pm 16 \%$ in the LIF sensitivity factor $(\alpha)$.

Individual zero determinations using zero air were performed over $90 \mathrm{~s}$ intervals, and the standard error of the $5 \mathrm{~Hz}$ data over this time was typically equivalent to $0.5 \mathrm{ppt} \mathrm{SO}_{2}$. Variations between subsequent zero determinations were typically around $1 \mathrm{ppt}$ or less. The zero value for each $5 \mathrm{~Hz}$ data point was approximated through linear interpolation between the two neighboring zero determinations. To estimate nonlinear drift of the zero between determinations, measurement data analyzed using all zero determinations were compared to data analyzed using only every second zero determination. This shows that the average additional uncertainty in the zero due to drift was up to $0.4 \mathrm{ppt}$. Since the $0.5 \mathrm{ppt}$ uncertainty from precision and $0.4 \mathrm{ppt}$ uncertainty from drift are not expected to be correlated, we state a \pm 0.9 ppt uncertainty in the zero for individual $5 \mathrm{~Hz}$ measurements.

\subsection{Precision}

VIRGAS data demonstrate that instrument precision is consistent with that expected from Poisson statistics of the PMT photon counts. Figure 11 shows an Allan deviation analysis of $1.2 \mathrm{~h}$ of data from the 28 October flight in the lower stratosphere over the continental US when the $\mathrm{SO}_{2}$ mixing ratio was steady at an average of $3.1 \mathrm{ppt}$. During this segment the measured background was $240 \mathrm{cps} \mathrm{mW}^{-1}$, the sensitiv-

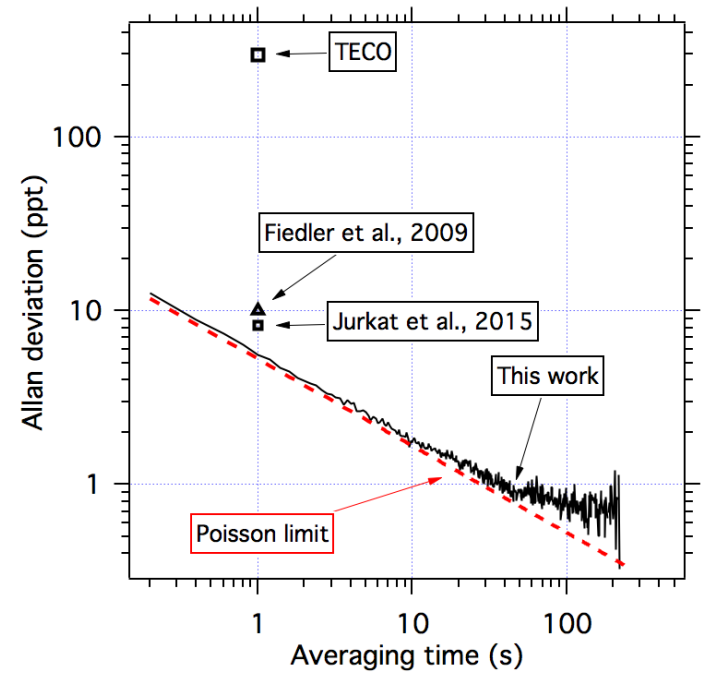

Figure 11. Instrument precision (Allan deviation) during a $1.2 \mathrm{~h}$ segment sampling an average $\mathrm{SO}_{2}$ abundance of $3.1 \mathrm{ppt}$ in the LS during the 28 October flight compared to the expected precision (Poisson limit). Other points show $1 \sigma$ precision values for a commercial pulsed-fluorescence instrument (TECO) and two CIMS instruments (Jurkat et al., 2015; Fiedler et al., 2009).
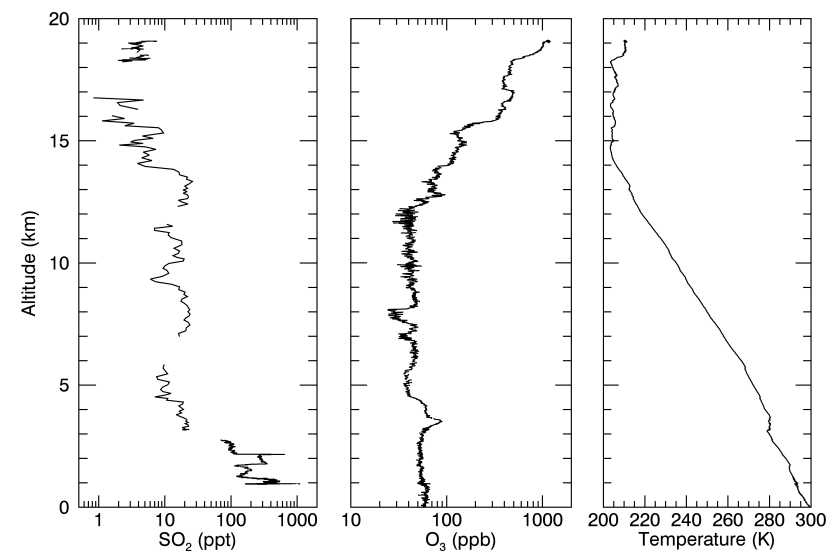

Figure 12. Data from final descent on 28 October. Left panel: $10 \mathrm{~s}$ averages shown above $3 \mathrm{~km}$, $1 \mathrm{~s}$ averages shown below $3 \mathrm{~km}$. Gaps in the $\mathrm{SO}_{2}$ data are during periods where instrument calibrations and zero measurements occurred.

ity was $2.1 \mathrm{cps} \mathrm{ppt}^{-1} \mathrm{~mW}^{-1}$ and the average laser power was $2.0 \mathrm{~mW}$. The precision yields a $1 \sigma$ detection limit of $2 \mathrm{ppt}$ for a $10 \mathrm{~s}$ averaging time. The expected noise level from Poisson statistics based on these parameters shown in the figure is in excellent agreement with the observed noise level. In addition, $1 \sigma$ detection limits are shown for two published CIMS $\mathrm{SO}_{2}$ measurements (Fiedler et al., 2009; Jurkat et al., 2016) as well as the value derived in our laboratory for a Thermo Environmental Model $43 \mathrm{C} \mathrm{SO}_{2}$ analyzer. To the best of our knowledge, the precision demonstrated in this work is the best reported precision for an ambient $\mathrm{SO}_{2}$ measurement. It 

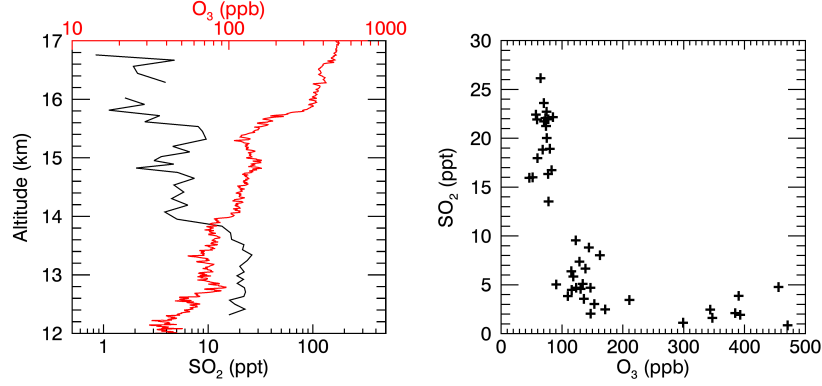

Figure 13. Data from final descent on 28 October in the range 12$17 \mathrm{~km}$. Left panel: $10 \mathrm{~s}$ average $\mathrm{SO}_{2}$ mixing ratios plotted against the bottom axis. $2 \mathrm{~Hz} \mathrm{O}_{3}$ plotted against the top axis. Right panel: $10 \mathrm{~s}$ averages of $\mathrm{SO}_{2}$ plotted against $\mathrm{O}_{3}$.

Table 1. Performance and physical specifications for operation of the $\mathrm{SO}_{2}$ instrument, the NASA WB-57F.

\begin{tabular}{ll}
\hline Size & $86 \times 60 \times 34 \mathrm{~cm}$ \\
\hline Weight & $90 \mathrm{~kg}$ \\
Max. power & Instrument: $300 \mathrm{~W}$ \\
& Pump: $300 \mathrm{~W}$ \\
& Heaters: $800 \mathrm{~W}$ \\
$1 \sigma$ precision & $2 \mathrm{ppt}, 10 \mathrm{~s}$ \\
Accuracy & $\pm(16 \%+0.9 \mathrm{ppt})$ \\
Time response & $0.1 \mathrm{~s}$ \\
\hline
\end{tabular}

is expected that, through achievable increases in laser power and further narrowing of the laser linewidth, the detection limit demonstrated here could improve by a factor of 2 or more.

Figure 12 shows a sample of the vertical $\mathrm{SO}_{2}$ profiles acquired during VIRGAS extending from $1 \mathrm{~km}$ above the surface to the lower stratosphere above $19 \mathrm{~km}$. This data segment is from October 28 on the final descent of the WB-57F into Ellington Field. Data shown are averaged to $1 \mathrm{~Hz}$ at $3 \mathrm{~km}$ and below and averaged to $0.1 \mathrm{~Hz}$ above $3 \mathrm{~km}$. The precision demonstrated here appears to be sufficient to resolve significant atmospheric variability and provide a comprehensive view of $\mathrm{SO}_{2}$ up to the lower stratosphere. Figure 13 shows just the segment between 12 and $17 \mathrm{~km}$. The relationship observed here in the UT-LS between $\mathrm{SO}_{2}$ and $\mathrm{O}_{3}$ supports the validity of the fine structure observed in $\mathrm{SO}_{2}$, as $\mathrm{SO}_{2}$ and $\mathrm{O}_{3}$ are anti-correlated in this region, presumably due to troposphere-stratosphere mixing in the extra-tropics (Pan et al., 2004).

\section{Summary}

A new in situ LIF-based $\mathrm{SO}_{2}$ instrument has been developed and demonstrated for measurements in the UT-LS. The instrument uses a novel custom-build fiber-based laser to produce typically $2-4 \mathrm{~mW}$ of power at $216.9 \mathrm{~nm}$. This power is sufficient for precise measurements at LIF cell pressures as low as $35 \mathrm{hPa}$, which is adequate for instrument operation at the maximum altitudes of high-altitude research aircraft (19$20 \mathrm{~km}$ ). The instrument is calibrated by $\mathrm{SO}_{2}$ standard addition and zeroed routinely in flight. The laboratory and flight data demonstrate that the current accuracy of the UT-LS $1 \mathrm{~Hz}$ measurements is $\pm(16 \%+0.9)$ ppt. Typical noise $(1 \sigma$ precision) at $1 \mathrm{~Hz}$ was $5-6 \mathrm{ppt}$. Averaging the data to $0.1 \mathrm{~Hz}$ provides a noise level of $2 \mathrm{ppt}$ ( $1 \sigma$ precision). In-flight UT-LS measurements on and off of an $\mathrm{SO}_{2}$ resonance at $216.9 \mathrm{~nm}$ indicate the absence of significant interferences from other non- $\mathrm{SO}_{2}$-fluorescing species.

Performance and physical specifications for the VIRGAS WB-57F instrument are summarized in Table 1. Although minimizing space, weight and power requirements were important considerations in the new flight instrument, they were not optimized. A reintegration of the $\mathrm{SO}_{2}$ instrument could significantly reduce each while maintaining or improving performance. Ongoing work to improve the laser operation is expected to improve stability of the laser power and wavelength, and to provide higher signal by narrowing the laser bandwidth to match the $\mathrm{SO}_{2}$ spectrum. Interference tests with aromatics that are known to fluoresce upon excitation in this region are planned to optimize operation and constrain the uncertainties when the instrument is used in polluted tropospheric regions.

A series of flights with the instrument integrated on the NASA WB-57F provided valuable engineering and scientific data, with the latter providing the most comprehensive in situ characterization of $\mathrm{SO}_{2}$ in the tropical UT-LS to date. Instrument precision appears sufficient to resolve significant atmospheric structure and hence to test global model predictions and satellite retrievals of $\mathrm{SO}_{2}$ in the UT-LS.

Acknowledgements. This research was funded by the NOAA Atmospheric Chemistry, Carbon Cycle, and Climate Program and by the NASA Radiation Sciences Program. We would like to thank the NASA WB-57F crew and management team for support during VIRGAS integration and flights. We thank K. Rosenlof, P. Newman and E. Ray for organization and flight planning during VIRGAS.

Edited by: D. Heard

Reviewed by: two anonymous referees

\section{References}

Ahmed, S. M. and Kumar, V.: Quantitative photoabsorption and flourescence spectroscopy of $\mathrm{SO}_{2}$ at $188-231$ and $278.7-320 \mathrm{~nm}$, J. Quant. Spectrosc. Ra., 47, 359-373, doi:10.1016/00224073(92)90038-6, 1992.

Bludský, O., Nachtigall, P., Hrušák, J., and Jensen, P.: The calculation of the vibrational states of $\mathrm{SO} 2$ in the $\widetilde{\mathrm{C}} 1 \mathrm{~B} 2$ electronic state up to the $\mathrm{SO}(3 \Sigma-)+\mathrm{O}(3 \mathrm{P})$ dissociation limit, Chem. Phys. Lett., 318, 607-613, doi:10.1016/S0009-2614(00)00015-4, 2000.

Bradshaw, J. D., Rodgers, M. O., and Davis, D. D.: Single photon laser-induced fluorescence detection of $\mathrm{NO}$ and $\mathrm{SO}_{2}$ for atmo- 
spheric conditions of composition and pressure, Appl. Optics, 21, 2493, doi:10.1364/AO.21.002493, 1982.

Brand, J. C. D. and Srikameswaran, K.: The $\Pi^{*}-\Pi(2350 \AA)$ band system of sulphur dioxide, Chem. Phys. Lett., 15, 130-132, doi:10.1016/0009-2614(72)87034-9, 1972.

Calvert, J. C.: $\mathrm{SO}_{2}, \mathrm{NO}$ and $\mathrm{NO}_{2}$ Oxidation Mechanisms: Atmospheric Considerations, 3rd ed., Butterworth Publishers, Stoneham, MA, USA, 1984.

Cazorla, M., Wolfe, G. M., Bailey, S. A., Swanson, A. K., Arkinson, H. L., and Hanisco, T. F.: A new airborne laser-induced fluorescence instrument for in situ detection of formaldehyde throughout the troposphere and lower stratosphere, Atmos. Meas. Tech., 8, 541-552, doi:10.5194/amt-8-541-2015, 2015.

Dentener, F., Kinne, S., Bond, T., Boucher, O., Cofala, J., Generoso, S., Ginoux, P., Gong, S., Hoelzemann, J. J., Ito, A., Marelli, L., Penner, J. E., Putaud, J.-P., Textor, C., Schulz, M., van der Werf, G. R., and Wilson, J.: Emissions of primary aerosol and precursor gases in the years 2000 and 1750 prescribed data-sets for AeroCom, Atmos. Chem. Phys., 6, 4321-4344, doi:10.5194/acp-64321-2006, 2006.

DiGangi, J. P., Boyle, E. S., Karl, T., Harley, P., Turnipseed, A., Kim, S., Cantrell, C., Maudlin III, R. L., Zheng, W., Flocke, F., Hall, S. R., Ullmann, K., Nakashima, Y., Paul, J. B., Wolfe, G. M., Desai, A. R., Kajii, Y., Guenther, A., and Keutsch, F. N.: First direct measurements of formaldehyde flux via eddy covariance: implications for missing in-canopy formaldehyde sources, Atmos. Chem. Phys., 11, 10565-10578, doi:10.5194/acp-1110565-2011, 2011.

Fiedler, V., Nau, R., Ludmann, S., Arnold, F., Schlager, H., and Stohl, A.: East Asian $\mathrm{SO}_{2}$ pollution plume over Europe - Part 1: Airborne trace gas measurements and source identification by particle dispersion model simulations, Atmos. Chem. Phys., 9, 4717-4728, doi:10.5194/acp-9-4717-2009, 2009.

Gao, R. S., McLaughlin, R. J., Schein, M. E., Neuman, J. A., Ciciora, S. J., Holecek, J. C., and Fahey, D. W.: Computercontrolled Teflon flow control valve, Rev. Sci. Instrum., 70, 4732, doi:10.1063/1.1150137, 1999.

Gao, R. S., Ballard, J., Watts, L. A., Thornberry, T. D., Ciciora, S. J., McLaughlin, R. J., and Fahey, D. W.: A compact, fast UV photometer for measurement of ozone from research aircraft, Atmos. Meas. Tech., 5, 2201-2210, doi:10.5194/amt-5-2201-2012, 2012.

Heckendorn, P., Weisenstein, D., Fueglistaler, S., Luo, B. P., Rozanov, E., Schraner, M., Thomason, L. W., and Peter, T.: The Impact of Geoengineering Aerosols on Stratospheric Temperature and Ozone, Environ. Res. Lett., 4, 045108, doi:10.1088/1748-9326/4/4/045108, 2011.

Heidt, L. E., Vedder, J. F., Pollock, W. H., Lueb, R. A., and Henry, B. E.: Trace gases in the Antarctic atmosphere, J. Geophys. Res., 94, 11599, doi:10.1029/JD094iD09p11599, 1989.

Hofmann, D., Barnes, J., O'Neill, M., Trudeau, M., and Neely, R.: Increase in background stratospheric aerosol observed with lidar at Mauna Loa Observatory and Boulder, Colorado, Geophys. Res. Lett., 36, 3-7, doi:10.1029/2009GL039008, 2009.

Hui, M.-H. and Rice, S. A.: Decay fluorescence from single vibronic levels of $\mathrm{SO}_{2}$, Chem. Phys. Lett., 20, 411-412, doi:10.1016/0009-2614(73)85186-3, 1973.

Jurkat, T., Kaufmann, S., Voigt, C., Schäuble, D., Jeßberger, P., and Ziereis, H.: The airborne mass spectrometer AIMS - Part
2: Measurements of trace gases with stratospheric or tropospheric origin in the UTLS, Atmos. Meas. Tech., 9, 1907-1923, doi:10.5194/amt-9-1907-2016, 2016.

Kirkby, J., Curtius, J., Almeida, J., Dunne, E., Duplissy, J., Ehrhart, S., Franchin, A., Gagné, S., Ickes, L., Kürten, A., Kupc, A., Metzger, A., Riccobono, F., Rondo, L., Schobesberger, S., Tsagkogeorgas, G., Wimmer, D., Amorim, A., Bianchi, F., Breitenlechner, M., David, A., Dommen, J., Downard, A., Ehn, M., Flagan, R. C., Haider, S., Hansel, A., Hauser, D., Jud, W., Junninen, H., Kreissl, F., Kvashin, A., Laaksonen, A., Lehtipalo, K. Lima, J., Lovejoy, E. R., Makhmutov, V., Mathot, S., Mikkilä, J., Minginette, P., Mogo, S., Nieminen, T., Onnela, A., Pereira, P., Petäjä, T., Schnitzhofer, R., Seinfeld, J. H., Sipilä, M., Stozhkov, Y., Stratmann, F., Tomé, A., Vanhanen, J., Viisanen, Y., Vrtala, A., Wagner, P. E., Walther, H., Weingartner, E., Wex, H., Winkler, P. M., Carslaw, K. S., Worsnop, D. R., Baltensperger, U., and Kulmala, M.: Role of sulphuric acid, ammonia and galactic cosmic rays in atmospheric aerosol nucleation, Nature, 476, 429-433, doi:10.1038/nature10343, 2011.

Koplow, J. P., Di Teodoro, F., Kliner, D. a. ., Moore, S. W., and Smith, A. V: Efficient second, third, fourth, and fifth harmonic generation of a Yb-doped fiber amplifier, Opt. Commun., 210, 393-398, doi:10.1016/S0030-4018(02)01825-4, 2002.

Kulmala, M., Kontkanen, J., Junninen, H., Lehtipalo, K., Manninen, H. E., Nieminen, T., Petaja, T., Sipila, M., Schobesberger, S., Rantala, P., Franchin, A., Jokinen, T., Jarvinen, E., Aijala, M., Kangasluoma, J., Hakala, J., Aalto, P. P., Paasonen, P., Mikkila, J., Vanhanen, J., Aalto, J., Hakola, H., Makkonen, U., Ruuskanen, T., Mauldin, R. L., Duplissy, J., Vehkamaki, H., Back, J., Kortelainen, A., Riipinen, I., Kurten, T., Johnston, M. V, Smith, J. N., Ehn, M., Mentel, T. F., Lehtinen, K. E. J., Laaksonen, A., Kerminen, V.-M., and Worsnop, D. R.: Direct Observations of Atmospheric Aerosol Nucleation, Science, 339, 943 946, doi:10.1126/science.1227385, 2013.

Lamarque, J.-F., Bond, T. C., Eyring, V., Granier, C., Heil, A., Klimont, Z., Lee, D., Liousse, C., Mieville, A., Owen, B., Schultz, M. G., Shindell, D., Smith, S. J., Stehfest, E., Van Aardenne, J., Cooper, O. R., Kainuma, M., Mahowald, N., McConnell, J. R., Naik, V., Riahi, K., and van Vuuren, D. P.: Historical (1850-2000) gridded anthropogenic and biomass burning emissions of reactive gases and aerosols: methodology and application, Atmos. Chem. Phys., 10, 7017-7039, doi:10.5194/acp10-7017-2010, 2010.

Lelieveld, J., Evans, J. S., Fnais, M., Giannadaki, D., and Pozzer, A.: The contribution of outdoor air pollution sources to premature mortality on a global scale, Nature, 525, 367-371, doi:10.1038/nature15371, 2015.

Manatt, S. L. and Lane, A. L.: A compilation of the absorption cross-sections of $\mathrm{SO}_{2}$ from 106 to $403 \mathrm{~nm}$, J. Quant. Spectrosc. Ra., 50, 267-276, doi:10.1016/0022-4073(93)90077-U, 1993.

Matsumi, Y., Shigemori, H., and Takahashi, K.: Laser-induced fluorescence instrument for measuring atmospheric $\mathrm{SO}_{2}$, Atmos. Environ., 39, 3177-3185, doi:10.1016/j.atmosenv.2005.02.023, 2005.

Mauldin III, R. L., Berndt, T., Sipilä, M., Paasonen, P., Petäjä, T., Kim, S., Kurtén, T., Stratmann, F., Kerminen, V.-M., and Kulmala, M.: A new atmospherically relevant oxidant of sulphur dioxide, Nature, 488, 193-196, doi:10.1038/nature11278, 2012. 
McNutt, M. K., Abdalati, W., Caldeira, K., Doney, S. C., Falkowski, P. G., Fetter, S., Fleming, J. R., Hamberg, S. P., Morgan, M. G., Penner, J. E., Pierrehumbert, R. T., Rasch, P. J., Russell, L. M., Snow, J. T., Titley, D. W., and Wilcox, J.: Climate Intervention: Reflecting Sunlight to Cool Earth, Washington DC, USA, 2015.

Myhre, G., Shindell, D., Bréon, F.-M., Collins, W., Fuglestvedt, J., Huang, J., Koch, D., Lamarque, J.-F., Lee, D., Mendoza, B., Nakajima, T., Robock, A., Stephens, G., Takemura, T., and Zhang, H.: Anthropogenic anc Natural Radiative Forcing, in: Climate Change 2013: The Physical Science Basis. Contribution of Working Group I to the Fifth Assessment Report of the Intergovernmental Panel on Climate Change, edited by: Stocker, T. F., Qin, D., Plattner, G.-K., Tignor, M., Allen, S. K., Boschung, J., Nauels, A., Xia, Y., Bex, V., and Midgley, P. M., Cambridge University Press, Cambridge, UK and New York, NY, USA., 2013.

Okabe, H.: Fluorescence and predissociation of sulfur dioxide, J. Am. Chem. Soc., 93, 7095-7096, doi:10.1021/ja00754a072, 1971.

Pan, L. L., Randel, W. J., Gary, B. L., Mahoney, M. J., and Hintsa, E. J.: Definitions and sharpness of the extratropical tropopause: A trace gas perspective, J. Geophys. Res.-Atmos., 109, 1-11, doi:10.1029/2004JD004982, 2004.

Pierce, J. R., Weisenstein, D. K., Heckendorn, P., Peter, T., and Keith, D. W.: Efficient formation of stratospheric aerosol for climate engineering by emission of condensible vapor from aircraft, Geophys. Res. Lett., 37, 2-6, doi:10.1029/2010GL043975, 2010.

Randel, W. J., Park, M., Emmons, L., Kinnison, D., Bernath, P., Walker, K. A., Boone, C., and Pumphrey, H.: Asian Monsoon Transport of Pollution to the Stratosphere, Science, 328, 611613, doi:10.1126/science.1182274, 2010.

Rufus, J., Stark, G., Smith, P. L., Pickering, J. C., and Thorne, A. P.: High-resolution photoabsorption cross section measurements of $\mathrm{SO}_{2}, 2: 220$ to $325 \mathrm{~nm}$ at $295 \mathrm{~K}$, J. Geophys. Res.-Planet, 108, 5011, doi:10.1029/2002JE001931, 2003.

Scott, S. G., Bui, T. P., Chan, K. R., and Bowen, S. W.: The Meteorological Measurement System on the NASA ER-2 Aircraft, J. Atmos. Ocean. Tech., 7, 525-540, doi:10.1175/15200426(1990)007<0525:TMMSOT>2.0.CO;2, 1990.

Seinfeld, J. H. and Pandis, S. H.: Atmospheric Chemistry and Physics: From Air Pollution to Climate Change, second., John Wiley \& Sons, Inc., Hoboken, New Jersey, USA, 2006.

Solomon, S., Daniel, J. S., Neely III, R. R., Vernier, J. P., Dutton, E. G., and Thomason, L. W.: The persistently variable "background" stratospheric aerosol layer and global climate change, Science, 333, 866-870, doi:10.1126/science.1206027, 2011.
Stark, G., Smith, P. L., Rufus, J., Thorne, A. P., Pickering, J. C., and Cox, G.: High-resolution photoabsorption cross-section measurements of $\mathrm{SO}_{2}$ at $295 \mathrm{~K}$ between 198 and $220 \mathrm{~nm}$, J. Geophys. Res.-Planet, 104, 16585-16590, doi:10.1029/1999JE001022, 1999.

Stocker, T. F., D. Qin, G.-K., Plattner, L. V., Alexander, S. K., Allen, N. L., Bindoff, F.-M., Bréon, J. a., Church, U., Cubasch, S., Emori, P., Forster, P., Friedlingstein, N., Gillett, J. M., Gregory, D. L., Hartmann, E., Jansen, B., Kirtman, R., Knutti, K., Krishna Kumar, P., Lemke, J., Marotzke, V., Masson-Delmotte, G. a., Meehl, I. I., Mokhov, S., Piao, V., Ramaswamy, D., Randall, M., Rhein, M., Rojas, C., Sabine, D., Shindell, L. D., Talley, D. G., and Xie, V., and S.-P.: Technical Summary, Clim. Chang. 2013 Phys. Sci. Basis. Contrib. Work. Gr. I to Fifth Assess. Rep. Intergov. Panel Clim. Chang., 33-115, doi:10.1017/CBO9781107415324.005, 2013.

Thornberry, T. D., Rollins, A. W., Gao, R. S., Watts, L. A., Ciciora, S. J., McLaughlin, R. J., and Fahey, D. W.: A two-channel, tunable diode laser-based hygrometer for measurement of water vapor and cirrus cloud ice water content in the upper troposphere and lower stratosphere, Atmos. Meas. Tech., 8, 211-224, doi:10.5194/amt-8-211-2015, 2015.

Vernier, J. P., Thomason, L. W., and Kar, J.: CALIPSO detection of an Asian tropopause aerosol layer, Geophys. Res. Lett., 38, 1-6, doi:10.1029/2010GL046614, 2011.

Vet, R., Artz, R. S., Carou, S., Shaw, M., Ro, C.-U., Aas, W., Baker, A., Bowersox, V. C., Dentener, F., Galy-Lacaux, C., Hou, A., Pienaar, J. J., Gillett, R., Forti, M. C., Gromov, S., Hara, H., Khodzher, T., Mahowald, N. M., Nickovic, S., Rao, P. S. P., and Reid, N. W.: A global assessment of precipitation chemistry and deposition of sulfur, nitrogen, sea salt, base cations, organic acids, acidity and pH, and phosphorus, Atmos. Environ., 93, 3 100, doi:10.1016/j.atmosenv.2013.10.060, 2014.

Wennberg, P. O., Cohen, R. C., Hazen, N. L., Lapson, L. B., Allen, N. T., Hanisco, T. F., Oliver, J. F., Lanham, N. W., Demusz, J. N., and Anderson, J. G.: Aircraft-borne, laser-induced fluorescence instrument for the in situ detection of hydroxyl and hydroperoxyl radicals, Rev. Sci. Instrum., 65, 1858-1876, doi:10.1063/1.1144835, 1994. 